\title{
Níveis de metionina + cistina digestíveis em rações para poedeiras no pico de produção
}

\author{
[Digestible methionine plus cystine levels in diets for laying hens at the production peak] \\ A. Geraldo ${ }^{1}$, A.G. Bertechini ${ }^{2}$, E.J. Fassani ${ }^{2}$, P.B. Rodrigues ${ }^{2}$ \\ ${ }^{1}$ Instituto Federal Minas Gerais - CEFET - Bambui, MG \\ ${ }^{2}$ Departamento de Zootecnia - UFLA \\ Caixa Postal 3037 \\ 37200-000 - Lavras, MG
}

\begin{abstract}
RESUMO
Avaliaram-se os efeitos de níveis de aminoácidos sulfurados digestíveis (AASD) sobre o desempenho e a qualidade interna e externa de ovos de 360 poedeiras de 25 a 41 semanas de idade. Foram formuladas seis dietas experimentais: cinco continham 0,$578 ; 0,636 ; 0,694 ; 0,752$ ou $0,810 \%$ de AASD, e em uma o nível de AASD foi o usualmente recomendado, cada tratamento com cinco repetições de 12 aves, em quatro períodos de avaliação de 28 dias cada. Melhores resultados para produção de ovos, conversão alimentar, massa de ovos e ovos viáveis foram obtidos com as aves que consumiram 729; 751; 801 e 730mg AASD/dia, respectivamente. A elevação dos níveis de AASD resultou em aumentos lineares no consumo de ração, no ganho de peso, nas porcentagens de gema e no extrato etéreo na gema. Nos ovos armazenados por sete dias, houve aumento linear da porcentagem de gema e decréscimo linear da porcentagem de casca, unidade Haugh e peso específico com a elevação dos níveis de AASD. Conclui-se que, para melhores produção e qualidade interna e externa de ovos, é necessário o consumo de $752 \mathrm{mg}$ de AASD ou de $864 \mathrm{mg}$ de aminoácidos sulfurados totais por ave/dia.
\end{abstract}

Palavras-chave: poedeira, metionina+cistina digestível, qualidade do ovo, desempenho

\begin{abstract}
An experiment was conduct using 360 laying hens to evaluate the dietary levels of digestible sulfur amino acids (DSAA) on performance and egg quality of hens from 25 to 41 weeks of age. Five experimental diets were formulated containing 0.578, 0.636, 0.694, 0.752, and 0.810\% of DSAA and one additional diet using the recommend level. Each treatment was replicated five times with 12 birds per replicate during four evaluation periods of 28 days each. The best results for egg production, feed conversion, egg mass yield, and viable eggs were obtained by birds that consumed 729, 751, 801, and 730 DSAA mg/day, respectively. Feed intake, weight gain, percentage of yolk, and lipid yolk linearly increased with increasing levels of DSAA. A linear increase in the percentage of yolk and a linear decrease on the percentage of shell weight, Haugh unit, and specific weight were observed with increasing levels of DSAA for eggs stored during seven days. It is concluded that for the best production and egg quality, a consumption of $752 \mathrm{mg}$ of DSAA or $864 \mathrm{mg}$ of total sulfur amino acid per bird per day is required.
\end{abstract}

Keywords: layer, digestible amino acids, egg quality, performance

\section{INTRODUÇÃO}

Os estudos de nutrição de poedeiras constantemente proporcionam melhoras na compreensão da relação entre a composição da dieta e o desempenho das aves. Outros fatores,

Recebido em 22 de outubro de 2009

Aceito em 2 de setembro de 2010

*Autor para correspondência (corresponding author)

E-mail: bertechini@dzo.ufla.br como o peso da ave no início de postura, a linhagem utilizada e a foto-estimulação, também influenciam o tamanho e o peso dos ovos. Relacionados à nutrição têm-se o efeito do consumo de energia e os níveis nutricionais de metionina (MET) e ácido linoleico presentes na ração. 
Segundo Leeson e Summers (2001), os fatores nutricionais mais importantes, conhecidos por afetar o tamanho do ovo, são a proteína, a adequação em aminoácidos na ração e o ácido linoleico. Segundo esses autores, cerca de $50 \%$ da matéria seca do ovo é proteína, por isso o suprimento de aminoácidos para a sua síntese é crítico no processo de produção de ovos.

Segundo Carey et al. (1991), aves que consumiram 330mg de MET/dia produziram ovos mais leves em relação às que consumiram $450 \mathrm{mg} / \mathrm{dia}$, mas não houve diferença nas demais características produtivas e na porcentagem de casca, albúmen e gema dos ovos. Esses valores correspondem ao consumo de 600 e $818 \mathrm{mg}$ de aminoácidos sulfurados totais (AAST)/dia. O consumo de 512mg de MET/dia (930mg de AAST/dia) resultou em maior peso e massa de ovos, bem como maior teor de sólidos na gema e albúmen, quando comparado à ingestão de apenas 326mg/dia (Shafer et al., 1996).

Shafer et al. (1998), em aves que consumiram de 413 a 556mg MET/ave/dia, observaram que o rendimento de componentes do albúmen na base de massa, no teor de sólidos e proteína aumentou com o aumento da ingestão da MET diária. Diferenças na produção de ovos, no consumo de ração e no peso específico não foram observadas por Roland et al. (2000) em aves leves que receberam ração com 0,$810 ; 0,760 ; 0,720 ; 0,690$ ou $0,650 \%$ de aminoácidos sulfurados totais (relação AAST/lisina constante em 0,82), e ocorreu aumento no peso dos ovos à medida que se elevaram os níveis de AAST.

Sohail et al. (2002) comprovaram o efeito da suplementação de aminoácidos em rações formuladas à base de proteína ideal usando a lisina como padrão. Rações com níveis crescentes de AAST $(0,650 ; 0,720$ e $0,810 \%)$ proporcionaram aumento linear no peso dos ovos e, também, aumento no consumo de ração, na produção e na conversão alimentar. Novak e Scheideler (2003) não encontraram diferenças quanto ao nível de proteína da ração $(14,4 ; 16,3$ e $18,9 \% \mathrm{~PB})$ e quanto a três relações AAST/lisina $(0,82 ; 0,85$ e 0,97$)$ para produção de ovos, ganho de peso, peso e massa de ovos, porcentagem e sólidos totais na gema, porcentagem de albúmen e unidade Haugh.

As recomendações das tabelas de exigências nutricionais também são divergentes. Enquanto o NRC (Nutrient..., 1994) recomenda 300mg de MET e 580mg de AAST/dia, Rostagno et al. (2005) indicam 400mg de MET e 735mg de AAST/dia, considerando-se o peso vivo das aves de $1600 \mathrm{~g}$, o ganho de peso diário de $0,5 \mathrm{~g}$ e a produção de massa de ovos/dia de $50 \mathrm{~g}$, valores estes bem mais altos que os indicados pelo NRC.

Apesar de a literatura trazer muitas informações importantes a respeito das recomendações desses aminoácidos, ainda existem controvérsias, principalmente com relação à qualidade interna e ao rendimento no processamento dos ovos. Assim, o presente trabalho teve como objetivo estudar o efeito de níveis de aminoácidos sulfurados digestíveis (AASD) sobre o desempenho e a qualidade de ovos de poedeiras comerciais brancas de 25 a 41 semanas de idade.

\section{MATERIAL E MÉTODOS}

Foram utilizadas 360 poedeiras da linhagem Hy Line - W36, de 25 a 41 semanas de idade, as quais receberam cinco dietas experimentais, formuladas de acordo com o NRC (Nutrient..., 1994): 0,578; 0,636; 0,694; 0,752 e $0,810 \%$ de AASD, isonutrientes, com exceção dos aminoácidos em estudo. Utilizou-se também um tratamento-controle, representado por uma dieta formulada de acordo com os níveis nutricionais recomendados por Rostagno et al. (2005), com nível de AASD de $0,771 \%$ (Tab. 1).

As análises dos teores de proteína bruta dos ingredientes básicos da ração (milho, farelo de soja e farelo de glúten) foram realizadas conforme metodologia AOAC (Association..., 1990).

O delineamento experimental utilizado foi inteiramente ao acaso, com seis tratamentos em parcela subdividida no tempo, com quatro períodos de 28 dias cada, cinco repetições e 12 aves por parcela.

Tabela 1. Composição das rações experimentais usadas para poedeiras segundo os tratamentos 


\begin{tabular}{|c|c|c|c|c|c|c|}
\hline \multirow{2}{*}{ Ingrediente } & \multicolumn{5}{|c|}{ AASD (\%) } & \multirow{2}{*}{$\frac{\text { Controle }(\%)}{0,771}$} \\
\hline & 0,578 & 0,636 & 0,634 & 0,752 & $\overline{0,810}$ & \\
\hline Milho & 62,910 & 62,910 & 62,910 & 62,910 & 62,910 & 59,653 \\
\hline Farelo de soja & 20,600 & 20,600 & 20,600 & 20,600 & 20,600 & 21,900 \\
\hline Farelo de glúten, $60 \%$ & 2,760 & 2,760 & 2,760 & 2,760 & 2,760 & 4,900 \\
\hline Óleo de soja & 2,350 & 2,350 & 2,350 & 2,350 & 2,350 & 2,360 \\
\hline $\mathrm{L}-\mathrm{Lisina}, 99 \%$ & - & - & - & - & - & 0,150 \\
\hline $\mathrm{L}-$ Triptofano, $98 \%$ & - & - & - & - & - & 0,024 \\
\hline DL - Metionina, $99 \%$ & 0,080 & 0,139 & 0,198 & 0,257 & 0,316 & 0,223 \\
\hline Calcário calcítico & 8,200 & 8,200 & 8,200 & 8,200 & 8,200 & 8,210 \\
\hline Fosfato bicálcico & 1,940 & 1,940 & 1,940 & 1,94 & 1,940 & 1,920 \\
\hline Caulim & 0,500 & 0,441 & 0,382 & 0,323 & 0,264 & - \\
\hline Suplemento vitamínico ${ }^{1}$ & 0,100 & 0,100 & 0,100 & 0,100 & 0,100 & 0,100 \\
\hline Suplemento mineral $^{2}$ & 0,100 & 0,100 & 0,100 & 0,100 & 0,100 & 0,100 \\
\hline Sal comum & 0,460 & 0,460 & 0,460 & 0,460 & 0,460 & 0,460 \\
\hline Total (kg) & 100,000 & 100,000 & 100,000 & 100,000 & 100,000 & 100,000 \\
\hline \multicolumn{7}{|c|}{ Composição calculada } \\
\hline Energia metabolizável (kcal/kg)) & 2900 & 2900 & 2900 & 2900 & 2900 & 2900 \\
\hline Proteína bruta $(\%)^{3}$ & 16,2 & 16,2 & 16,2 & 16,2 & 16,2 & 17,81 \\
\hline Metionina digestível (\%) & 0,335 & 0,393 & 0,451 & 0,509 & 0,567 & 0,507 \\
\hline Metionina+cistina digestível (\%) & 0,578 & 0,636 & 0,694 & 0,752 & 0,810 & 0,771 \\
\hline Lisina digestível (\%) & 0,683 & 0,683 & 0,683 & 0,683 & 0,683 & 0,847 \\
\hline Ácido linoleico & 2,605 & 2,605 & 2,605 & 2,605 & 2,605 & 2,597 \\
\hline Cálcio (\%) & 3,70 & 3,70 & 3,70 & 3,70 & 3,70 & 3,7 \\
\hline Fósforo disponível (\%) & 0,45 & 0,45 & 0,45 & 0,45 & 0,45 & 0,45 \\
\hline Sódio (\%) & 0,20 & 0,20 & 0,20 & 0,20 & 0,20 & 0,20 \\
\hline Cloro & 0,317 & 0,317 & 0,317 & 0,317 & 0,317 & 0,317 \\
\hline Potássio & 0,557 & 0,557 & 0,557 & 0,557 & 0,557 & 0,557 \\
\hline
\end{tabular}

AASD: aminoácidos sulfurados digestivos.

${ }^{1}$ Suplementação vitamínica por kg de ração: vit.A: 8.000UI; vit. D3: 2.000UI; vit.E: 15UI; vit.K3: 2mg; vit.B2: 4mg; vit.B6: 1mg; vit.B12: $10 \mu \mathrm{g}$; niacina: 19,9mg; ácido pantotênico: 5,350mg; ácido fólico: 0,200mg.

${ }^{2}$ Suplementação mineral por kg de ração: manganês: $75 \mathrm{mg}$; zinco: $70 \mathrm{mg}$; ferro: $50 \mathrm{mg}$; cobre: $80 \mathrm{mg}$; iodo: $1,5 \mathrm{mg}$; cobalto: $0,200 \mathrm{mg}$, selênio: $0,250 \mathrm{mg}$.

${ }^{3}$ Valor da PB calculado sem a contribuição dos aminoácidos sintéticos.

${ }^{4}$ Ração formulada para consumo de $90 \mathrm{~g} / \mathrm{ave} / \mathrm{dia}$.

${ }^{5}$ Valor do AASD indicado por Rostagno et al. (2005).

Foram avaliados: produção (\%/ave/dia) e peso dos ovos $(\mathrm{g})$, consumo de ração $(\mathrm{g})$, massa de ovos (\% produção de ovos x peso dos ovos), conversão alimentar por massa de ovos (consumo de ração/ peso dos ovos x produção de ovos), ganho de peso das aves (g), ovos viáveis para consumo (produção de ovos - perda de ovos) e perda de ovos por trincas, quebrados, de casca mole e sem casca. Todas as medidas foram obtidas semanalmente, sendo considerados os resultados médios a cada 28 dias de avaliação.

A qualidade interna dos ovos (unidade Haugh) foi determinada nos últimos três dias de cada período de 28 dias, procedendo-se à análise de três ovos amostrados no dia, por parcela. Os ovos foram pesados em balança de precisão de $0,1 \mathrm{~g}$ e quebrados sobre uma superfície plana de vidro para a obtenção da altura do albúmen, medida pelo aparelho Technical Services and Supplies $\mathrm{QCM}+$, digital, com precisão de $0,1 \mathrm{~mm}$. Outros três ovos por parcela foram coletados para posterior quebra, após sete dias de armazenamento. Os valores de unidade Haugh foram calculados segundo a fórmula apresentada por Card e Nesheim (1966).

Para determinação do peso específico, todos os ovos íntegros produzidos nos últimos dois dias de cada período foram imersos e avaliados em 10 soluções de $\mathrm{NaCl}$, com densidade que variou de 1.066 a $1.102 \mathrm{~g} / \mathrm{cm}^{3}$, e gradiente de 0,004 entre elas. Os três ovos amostrados de cada parcela ao final de cada período, depois de quebrados para 
avaliação da unidade Haugh, tiveram suas cascas com as membranas lavadas em água e secas em estufa a $65^{\circ} \mathrm{C}$ por 72 horas. As cascas secas foram pesadas e, então, obteve-se a porcentagem dividindo-se o peso da casca pelo peso do ovo. $\mathrm{O}$ mesmo procedimento foi adotado para o cálculo da porcentagem de gema e albúmen.

Para a determinação da porcentagem de gema dos ovos frescos e armazenados por sete dias, utilizou-se metodologia indicada por Ahn et al. (1997). O conteúdo de sólidos totais na gema e albúmen foi determinado mediante pré-secagens a $55^{\circ} \mathrm{C}$ em estufa ventilada e a $105^{\circ} \mathrm{C}$ para secagem definitiva. A gema e o albúmen de três ovos quebrados foram separados e armazenados em potes plásticos e acondicionados no freezer a $-20^{\circ} \mathrm{C}$. No dia seguinte foi realizada a pesagem dessas amostras em pratos de alumínio, as quais foram anotadas em planilha adequada e levadas para estufa de ventilação forçada a $55^{\circ} \mathrm{C}$ por 72 horas.

Os dados obtidos foram submetidos à análise estatística utilizando-se o software SISVAR, descrito por Ferreira (2000), procedendo-se às análises de regressão para níveis de AASD, teste Dunnet para comparar o nível de suplementação com o controle e teste Tukey para os quatro períodos de 28 dias cada. Os testes compararam médias a $5 \%$ de probabilidade.

\section{RESULTADOS E DISCUSSÃO}

Na Tab. 2, estão apresentados os valores médios das características de desempenho avaliadas.

Tabela 2. Produção de ovos (PO), consumo de ração (CR), ganho de peso (GP), conversão alimentar (CA), massa de ovos (MO) e ovos viáveis (OV) de acordo com os tratamentos, em poedeiras de 25 a 41 semanas de idade

\begin{tabular}{|c|c|c|c|c|c|c|c|}
\hline \multirow{2}{*}{ Característica } & \multicolumn{5}{|c|}{$\operatorname{AASD}(\%)$} & \multirow{2}{*}{$\begin{array}{c}\text { Controle }(\%)^{7} \\
0,771\end{array}$} & \multirow{2}{*}{$\begin{array}{l}\text { CV } \\
(\%)\end{array}$} \\
\hline & 0,578 & 0,636 & 0,694 & 0,752 & 0,810 & & \\
\hline PO (\%/ave/dia) ${ }^{1}$ & 86,43 & $90,18^{*}$ & $92,14 *$ & $93,10^{*}$ & $91,15^{*}$ & 93,27 & 4,39 \\
\hline $\mathrm{CR}(\mathrm{g} / \mathrm{ave} / \mathrm{dia})^{2}$ & $95,25^{*}$ & $96,85^{*}$ & $98,55^{*}$ & $99,25 *$ & $101,10 *$ & 97,95 & 5,35 \\
\hline $\mathrm{GP}(\mathrm{g})^{3}$ & 63,7 & 66,8 & 88,9 & $117,9 *$ & $126,1 *$ & 123,5 & 10,4 \\
\hline $\mathrm{CA}(\mathrm{g} / \mathrm{g})^{4}$ & 2,06 & 1,97 & 1,91 & $1,88 *$ & 1,91 & 1,85 & 3,58 \\
\hline MO (g/ave/dia) ${ }^{5}$ & 46,50 & 49,36 & $51,83 *$ & $52,79 *$ & $53,1 *$ & 53,18 & 6,23 \\
\hline OV (\%/ave/dia $)^{6}$ & 85,72 & $89,22 *$ & $91,29 *$ & $92,22 *$ & $90,32 *$ & 92,30 & 4,14 \\
\hline
\end{tabular}

AASD: aminoácidos sulfurados digestíveis.

*Média estatisticamente igual à do controle pelo teste Dunnet $(\mathrm{P}>0,05)$.

${ }^{1}$ Regressão para níveis de 0,578 a $0,810 \%$ de AASD: efeito quadrático: $Y=-49,2457+386,8047 x-263,3239 x^{2}$; $\mathrm{R}^{2}=99,15 \%(\mathrm{P}<0,01), \mathrm{Y}^{\prime}=0,735 \%$.

${ }^{2}$ Regressão para níveis de 0,578 a $0,810 \%$ de AASD: efeito linear: $\mathrm{Y}=81,3286+24,3104 \mathrm{x} ; \mathrm{R}^{2}=98,62 \%(\mathrm{P}<0,05)$.

${ }^{3}$ Regressão para níveis de 0,578 a $0,810 \%$ de AASD: efeito linear: $Y=53,8812-198,4017 x ; R^{2}=95,01 \%(P<0,01)$.

${ }^{4}$ Regressão para níveis de 0,578 a $0,810 \%$ de AASD: efeito quadrático: $Y=5,2885-9,0806 x+6,0621 x^{2} ; R^{2}=99,68 \%$ $\left(\mathrm{P}<0,01, \mathrm{Y}^{\prime}=0,749 \%\right.$.

${ }^{5}$ Regressão para níveis de 0,578 a $0,810 \%$ de AASD: efeito quadrático: Y=-35,9506+223,7924x-140,5639x ; $\mathrm{R}^{2}=99,80 \%(\mathrm{P}<0,05), \mathrm{Y}^{\prime}=0,796 \%$.

${ }^{6}$ Regressão para níveis de 0,578 a $0,810 \%$ de AASD: efeito quadrático: $Y=-45,4083+373,3844 x-253,8432 x^{2}$; $\mathrm{R}^{2}=98,99 \%(\mathrm{P}<0,01), \mathrm{Y}^{\prime}=0,735 \%$.

${ }^{7}$ Valor de AASD indicado por Rostagno et al. (2005).

Os níveis de AASD na dieta influenciaram a produção de ovos $(\mathrm{P}<0,01)$ - efeito quadrático -, com maior produção de ovos em $0,735 \%$ de AASD na dieta, que correspondeu ao consumo de 729mg de AASD ave/dia ou $838 \mathrm{mg}$ de AAST/ave/dia (Tab. 2). A melhor produção de ovos em aves que receberam dieta com maiores níveis de AASD é justificada pela maior exigência por estes aminoácidos para sustentar as funções fisiológicas e produtivas (Ishibashi e Yonemochi, 2003). Estes resultados são diferentes dos obtidos por Novak et al. (2004) e Liu et al. (2005), que não encontraram diferenças na produção de ovos ao variarem o conteúdo desses aminoácidos de 550 a 700mg/dia.

O tratamento-controle, $0,771 \%$ de AASD, mostrou-se superior $(\mathrm{P}<0,05)$ na produção de ovos (Tab. 2) somente em relação ao tratamento com $0,578 \%$ de AASD. Os resultados indicaram que as exigências de AAST recomendadas pelo 
NRC (Nutrient..., 1994) encontram-se subestimados $(0,578 \%)$.

Houve diferença significativa $(\mathrm{P}<0,01)$ entre períodos quanto à produção de ovos, sendo a melhor produção obtida no período I, e produções iguais nos períodos II e IV (Tab. 3). No período III, ocorreu queda na produção de ovos decorrente da queda brusca na temperatura ambiente (média de 25,6 para $19,5^{\circ} \mathrm{C}$ ). Este fato pode ter aumentando as necessidades de energia para mantença e reduzido a energia para a formação do ovo. Apesar do aumento significativo do consumo de ração em relação à fase anterior, ainda assim, isso não foi suficiente para a manutenção da produção de ovos. A diminuição na produção de ovos ao longo dos períodos estudados era esperada e pode ser atribuída ao fato de as aves tornarem-se mais velhas, com diminuição progressiva na taxa de postura.

Tabela 3. Produção de ovos (PO), consumo de ração (CR), conversão alimentar (CA), massa de ovos (MO) e ovos viáveis (OV) segundo o período experimental

\begin{tabular}{lccccc}
\hline \multicolumn{1}{c}{ Período } & $\begin{array}{c}\text { PO } \\
(\% / a v e / d i a)\end{array}$ & $\begin{array}{c}\text { CR } \\
(\text { g/ave/dia })^{1}\end{array}$ & $\begin{array}{c}\text { CA } \\
(\mathrm{g} / \mathrm{g})^{1}\end{array}$ & $\begin{array}{c}\text { MO } \\
(\mathrm{g} / \mathrm{ave} / \mathrm{dia})^{1}\end{array}$ & $\begin{array}{c}\text { OV } \\
(\% / \mathrm{ave} / \mathrm{dia})^{11}\end{array}$ \\
\hline I (25-29 sem) & $94,18 \mathrm{a}$ & $93,47 \mathrm{c}$ & $1,84 \mathrm{a}$ & $50,93 \mathrm{bc}$ & $93,17 \mathrm{a}$ \\
II (30-33 sem) & $92,08 \mathrm{~b}$ & $96,77 \mathrm{~b}$ & $1,91 \mathrm{~b}$ & $51,11 \mathrm{~b}$ & $91,26 \mathrm{ab}$ \\
III (34-37 sem) & $87,61 \mathrm{c}$ & $100,80 \mathrm{a}$ & $2,03 \mathrm{c}$ & $49,86 \mathrm{c}$ & $89,51 \mathrm{~b}$ \\
IV (38-41 sem) & $90,32 \mathrm{~b}$ & $101,60 \mathrm{a}$ & $1,94 \mathrm{~b}$ & $52,60 \mathrm{a}$ & $86,77 \mathrm{c}$ \\
\hline
\end{tabular}

Médias seguidas por letras diferentes na coluna diferem entre si pelo teste Tukey $(\mathrm{P}<0,01)$. sem: semanas.

Houve efeito significativo $(\mathrm{P}<0,05)$ da inclusão de AASD sobre o consumo de ração, com efeito linear crescente com o aumento nos níveis da dieta, e não foi observada diferença $(\mathrm{P}>0,05)$ entre $\mathrm{o}$ tratamento-controle e os demais tratamentos (Tab. 2). Estes resultados são semelhantes aos de Baião et al. (1999) e Sohail et al. (2002), os quais observaram maior consumo de ração em aves que receberam ração com maior nível de AASD. Resultados diferentes foram obtidos por Novak et al. (2004) e Liu et al. (2005), que não observaram diferenças no consumo de aves que receberam diferentes níveis de AASD total nas dietas. Essa diferença no consumo de ração com o aumento nos níveis de aminoácidos sulfurados pode ser atribuída ao não balanceamento de aminoácidos nas dietas com menor conteúdo desses aminoácidos, resultando em aumento no consumo à medida que houve melhora na adequação aminoacídica delas.

Os resultados obtidos para consumo de ração indicaram diferenças significativas $(\mathrm{P}<0,01)$ entre períodos (Tab. 3), pois ocorreu aumento com o avanço da idade das aves, fato já esperado.

Foi observado efeito linear crescente $(\mathrm{P}<0,01)$ dos níveis de AASD sobre o ganho de peso das aves (Tab. 2). Este resultado pode ser explicado pelo aumento do consumo de ração observado à medida que foram aumentados os níveis dietéticos desses aminoácidos. Resultados semelhantes foram observados por Calderon e Jensen (1990) e Novak et al. (2004). Liu et al. (2005) não observaram diferenças no peso corporal de aves, e somente aves que consumiram dieta com 0,752 e $0,810 \%$ de AASD apresentaram ganho de peso semelhante às do controle.

Foi observado efeito quadrático $(\mathrm{P}<0,01)$ da inclusão de AASD na ração sobre a conversão alimentar, pois o melhor valor foi obtido com $0,749 \%$ de AASD na ração, ou consumo de $751 \mathrm{mg}$ AASD/ave/dia. Calderon e Jensen (1990) e Novak et al. (2004) também observaram melhora na conversão alimentar em aves que receberam dietas com níveis crescentes de AAST. Já Penz e Jensen (1991) e Liu et al. (2005) não observaram efeito do nível de AASD sobre a conversão alimentar das aves. Comparando o tratamento-controle com os demais tratamentos, somente o nível de $0,752 \%$ de AASD na ração apresentou conversão alimentar semelhante à do controle $(\mathrm{P}<0,05)$; os demais tratamentos foram piores.

Houve diferença significativa $(\mathrm{P}<0,01)$ entre períodos experimentais quanto à conversão alimentar, sendo o pior resultado observado no período III, devido ao menor valor também 
observado quanto à massa de ovos, neste período (Tab. 3).

A massa de ovos/ave/dia (Tab. 2) foi influenciada pelo nível de AASD - efeito quadrático $(\mathrm{P}<0,05)-$, sendo a maior massa de ovos obtida com o nível dietético de $0,796 \%$ de AASD, que resultou em consumo de $801 \mathrm{mg}$ AASD ou 920mg AASD total/ave/dia. Resultados semelhantes foram obtidos por Calderon e Jensen (1990) e Scheideler e Elliot (1998), que observaram melhor massa de ovos em aves que consumiram maior quantidade diária de AAST.

Comparando-se o tratamento-controle com os demais tratamentos, observou-se que somente os níveis de AASD na ração de 0,578 e $0,636 \%$ apresentaram menor produção de massa, e os demais tratamentos não diferiram do controle. Harms et al. (1998) indicaram que o conteúdo interno dos ovos aumentou com a suplementação de metionina na ração.
O período experimental influenciou a produção de massa de ovos $(\mathrm{P}<0,01)$ ao apresentar a melhor produção no período IV e a menor no período III (Tab. 3). A maior massa de ovos no decorrer dos períodos experimentais pode ser atribuída ao aumento da deposição de gema e albúmen, proporcionando, assim, melhor aproveitamento do ovo para posterior processamento.

A produção de ovos viáveis para consumo foi influenciada pela inclusão de AASD na ração $(\mathrm{P}<0,01)$ - comportamento quadrático -, com melhor produção de ovos viáveis no nível de $0,735 \%$ de AASD na ração, que corresponde ao consumo por ave de $730 \mathrm{mg}$ AASD/dia ou $839 \mathrm{mg}$ AAST/ave/dia (Tab. 2). O período experimental influenciou a produção de ovos viáveis $(\mathrm{P}<0,01)$, ao mostrar decréscimo em ovos viáveis com o avanço da idade das aves atribuído à redução na produção de ovos (Tab. 3).

$\mathrm{Na}$ Tab. 4, são apresentados resultados de rendimento e qualidade interna dos ovos.

Tabela 4. Porcentagens de gema, albúmen, casca e unidade Haugh (UH) de ovos frescos, proteína bruta do albúmen (PB albúmen) e extrato etéreo da gema (EE) na base de matéria seca e sólidos totais do albúmen (ST albúmen) e da gema (ST gema) dos ovos de acordo com os tratamentos, em poedeiras de 25 a 41 semanas de idade

\begin{tabular}{lccccccc}
\hline \multirow{2}{*}{ Característica } & \multicolumn{3}{c}{ AASD (\%) } & \multicolumn{3}{c}{ Controle (\%) } & CV \\
\cline { 2 - 6 } & 0,578 & 0,636 & 0,694 & 0,752 & 0,810 & 0,771 & $(\%)$ \\
\hline Gema $(\%)$ & $23,9)^{*}$ & $24,27^{*}$ & $24,04^{*}$ & $24,75^{*}$ & $24,91^{*}$ & 24,23 & 3,47 \\
Albúmen (\%) & $66,58^{*}$ & $66,44^{*}$ & $66,74^{*}$ & $66,22^{*}$ & $66,02^{*}$ & 66,72 & 1,31 \\
Casca $(\%)^{2}$ & 9,57 & $9,28^{*}$ & $9,22^{*}$ & $9,03^{*}$ & $9,08^{*}$ & 9,04 & 4,09 \\
UH $^{3}$ & 99,88 & 99,51 & $98,58^{*}$ & $98,26^{*}$ & 98,82 & 96,53 & 2,57 \\
PB albúmen (\%) & $88,77^{*}$ & $89,15^{*}$ & $89,24^{*}$ & $88,87^{*}$ & $89,14^{*}$ & 88,85 & 2,57 \\
EE gema (\%) & 57,089 & $58,37^{*}$ & $58,85^{*}$ & $59,54^{*}$ & 60,34 & 59,05 & 1,78 \\
ST albúmen (\%) & $11,99^{*}$ & $12,11^{*}$ & $12,07^{*}$ & $12,16^{*}$ & $12,17^{*}$ & 12,16 & 3,19 \\
ST gema (\%) & $50,54^{*}$ & $51,00^{*}$ & $50,99^{*}$ & $51,23^{*}$ & $51,21^{*}$ & 50,86 & 1,51 \\
\hline
\end{tabular}

AASD: aminoácidos sulfurados digestíveis.

*Médias estatisticamente iguais à do controle pelo teste Dunnet $(\mathrm{P}<0,05)$.

${ }^{1}$ Regressão para níveis de 0,578 a 0,810\% de AASD: efeito linear: $\mathrm{Y}=21,6256+3,9862 \mathrm{x} ; \mathrm{R}^{2}=77,03 \%(\mathrm{P}<0,01)$.

${ }^{2}$ Regressão para níveis de 0,578 a $0,810 \%$ de AASD: efeito linear: $\mathrm{Y}=10,6937-2,1034 \mathrm{x} ; \mathrm{R}^{2}=83,80 \%(\mathrm{P}<0,01)$.

${ }^{3}$ Efeito significativo dos níveis de AASD ( $\left.\mathrm{P}<0,01\right)$.

${ }^{4}$ Regressão para níveis de 0,578 a 0,810\% de AASD: efeito linear: $\mathrm{Y}=49,6561+13,2285 \mathrm{x} ; \mathrm{R}^{2}=97,69 \%(\mathrm{P}<0,01)$.

Houve efeito linear crescente $(\mathrm{P}<0,01)$ dos níveis de AASD na ração sobre a porcentagem de gema em ovos frescos (Tab. 4). Estes resultados diferem dos obtidos por Novak et al. (2004) e Liu et al. (2005), que não observaram efeito dos níveis de AASD sobre esta variável. Quanto ao período experimental, observou-se que a porcentagem de gema aumentou com o avançar do período. Estes resultados assemelham-se aos encontrados por Fletcher et al. (1981), que atribuíram maior deposição de gema em relação ao albúmen à medida que as aves se tornaram mais velhas.

Não houve efeito significativo $(\mathrm{P}>0,05)$ dos níveis de AASD na ração sobre a porcentagem 
de albúmen nos ovos frescos (Tab. 4). Os resultados foram semelhantes aos encontrados por Scheideler e Elliot (1998) e Novak et al. (2004).

Houve efeito significativo dos níveis de AASD na ração sobre a porcentagem de casca em ovos frescos $(\mathrm{P}<0,01)$ com efeito linear decrescente dos níveis sobre a porcentagem de casca (Tab. 4). Somente o nível de $0,578 \%$ de AASD na ração resultou em maior porcentagem de casca $(\mathrm{P}<0,05)$. Carey et al. (1991), Scheideler e Elliot (1998), Novak et al. (2004) e Liu et al. (2005) não encontraram efeito dos níveis de AAST na ração sobre a porcentagem de casca.

Quanto à unidade Haugh (UH), observou-se que houve efeito significativo $(\mathrm{P}<0,01)$ dos níveis de AASD sobre esta variável; o tratamento-controle apresentou valores semelhantes $(\mathrm{P}>0,05)$ aos encontrados nos níveis de $0,694 \%$ e $0,752 \%$ de AASD na ração, e os demais tratamentos resultaram em melhores valores de $\mathrm{UH}$, se comparados ao controle (Tab. 4). Na análise das variáveis relacionadas ao rendimento no processamento, não houve efeito significativo $(\mathrm{P}>0,05)$ dos níveis de AASD na ração sobre a porcentagem de proteína bruta no albúmen, isto é, o tratamento-controle foi semelhante aos demais tratamentos. Estes resultados foram semelhantes aos encontrados por Novak et al. (2004). Shafer et al. (1998) observaram maior porcentagem de $\mathrm{PB}$ no albúmen em aves que consumiram $815 \mathrm{mg}$ de AASD total/dia em relação às que consumiram 718 e $849 \mathrm{mg}$.

Houve efeito significativo dos níveis de AASD sobre o teor de extrato etéreo na gema, efeito linear crescente $(\mathrm{P}<0,01)$ (Tab. 4).

As variáveis sólidos totais na gema e albúmen, que são de grande importância no processamento de ovos, não foram influenciadas pelos níveis de AASD fornecidos na ração $(\mathrm{P}>0,05)$, isto é, o tratamento-controle resultou em valores iguais estatisticamente aos dos demais tratamentos estudados (Tab. 4). Resultados semelhantes foram obtidos por Novak e Scheideler (2003) e Liu et al. (2005).

Os resultados de qualidade externa dos ovos frescos e qualidade interna de ovos armazenados em temperatura ambiente por sete dias são apresentados na Tab. 5 .

Tabela 5. Porcentagens de gema, albúmen e casca, unidade Haugh (UH) de ovos armazenados em temperatura ambiente por sete dias e peso específico (PE) de ovos de acordo com os tratamentos, em poedeiras de 25 a 41 semanas de idade

\begin{tabular}{|c|c|c|c|c|c|c|c|}
\hline \multirow{2}{*}{ Característica } & \multicolumn{5}{|c|}{ AASD (\%) } & \multirow{2}{*}{$\begin{array}{c}\text { Controle }(\%)^{5} \\
0,771\end{array}$} & \multirow{2}{*}{$\begin{array}{l}\mathrm{CV} \\
(\%)\end{array}$} \\
\hline & 0,578 & 0,636 & 0,694 & 0,752 & 0,810 & & \\
\hline $\operatorname{Gema}(\%)^{1}$ & $25,14^{*}$ & $25,36^{*}$ & $25,33^{*}$ & $25,89 *$ & $26,10^{*}$ & 25,43 & 3,52 \\
\hline Albúmen (\%) & $65,20^{*}$ & $65,18 *$ & $65,33^{*}$ & $64,87 *$ & $64,74^{*}$ & 65,30 & 1,56 \\
\hline $\operatorname{Casca}(\%)^{2}$ & 9,68 & $9,47 *$ & $9,34 *$ & $9,24 *$ & $9,21 *$ & 9,27 & 4,12 \\
\hline $\mathrm{UH}^{3}$ & 79,23 & 76,78 & 75,91 & 75,59 & $73,80^{*}$ & 73,08 & 3,55 \\
\hline $\operatorname{PE}(\%)^{4}$ & 1,092 & $1,090^{*}$ & $1,089 *$ & $1,088 *$ & $1,088^{*}$ & 1,088 & 0,22 \\
\hline
\end{tabular}

* Média estatisticamente igual a do controle pelo teste Dunnet $(\mathrm{P}<0,05)$.

${ }^{1}$ Regressão para níveis de 0,578 a $0,810 \%$ de AASD: efeito linear: $\mathrm{Y}=22,6317+4,2250 \mathrm{x} ; \mathrm{R}^{2}=89,56 \%(\mathrm{P}<0,05)$.

${ }^{2}$ Regressão para níveis de 0,578 a $0,810 \%$ de AASD: efeito linear: $Y=10,7783-2,0043 x ; R^{2}=92,64 \%(P<0,01)$.

${ }^{3}$ Regressão para níveis de 0,578 a 0,810\% de AASD: efeito linear: $Y=90,6683-20,7598 x ; R^{2}=92,41 \%(P<0,01)$.

${ }^{4}$ Regressão para níveis de 0,578 a $0,810 \%$ de AASD: efeito linear: $\mathrm{Y}=1,1015-0,0173 \mathrm{x} ; \mathrm{R}^{2}=92,94 \%(\mathrm{P}<0,01)$.

${ }^{5}$ Valor de AASD indicado por Rostagno et al. (2005).

Como observado em ovos frescos, houve efeito linear crescente $(\mathrm{P}<0,05)$ dos níveis de AASD na ração sobre a porcentagem de gema nos ovos armazenados por sete dias. Não se observou diferença significativa entre tratamentos $(\mathrm{P}>0,05)$ quanto à porcentagem de gema nos ovos. Os valores das porcentagens de albúmen e da casca de ovos armazenados foram semelhantes aos encontrados com ovos frescos.

Para a variável unidade Haugh de ovos armazenados por sete dias, ocorreu efeito linear decrescente $(\mathrm{P}<0,01)$ com o aumento da inclusão de AASD (Tab. 5). Esta piora neste valor pode ser atribuída à piora da qualidade de casca dos 
ovos (redução da \% de casca) com a elevação dos teores desses aminoácidos. Comparando-se o tratamento controle com os demais tratamentos, observou-se que somente as aves que receberam $0,810 \%$ de AASD na dieta apresentaram valores semelhantes de unidade Haugh, sendo os demais tratamentos superiores ao tratamento-controle (Tab. 5).

\section{CONCLUSÃo}

O consumo de $752 \mathrm{mg}$ de AASD, correspondente a 864mg de AAST/ave/dia, é recomendado para maximizar o desempenho e a qualidade interna e externa dos ovos de poedeiras leves no período de 25 a 41 semanas de idade.

\section{AGRADECIMENTOS}

À Hy-Line do Brasil, pela doação das pintainhas; ao $\mathrm{CNPq}$ por financiar a pesquisa e à FAPEMIG, pelo apoio a esta publicação.

\section{REFERÊNCIAS BIBLIOGRÁFICAS}

AHN, D.U.; KIM, S.M.; SHU, H. Effect of egg size and strain and age of hens on solids content of chicken eggs. Poult. Sci., v.76, p.914-919, 1997.

BAIÃO, N.C.; FERREIRA, M.O.O.; BORGES, F.M.O. et al. Efeito dos níveis de metionina da dieta sobre o desempenho de poedeiras comerciais. Arq. Bras. Med. Vet. Zootec., v.51, p.271-274, 1999.

CALDERON, V.M.; JENSEN, L.S. The requirement for sulfur amino acid by laying hens as influenced by the protein concentration. Poult. Sci., v.69, p.934-944, 1990.

CARD, L.E.; NESHEIM, M.C. Poultry production. 10.ed. Philadelphia: Lea e Febiger, 1966. 400p.

CAREY, J.B.; ASHER, R.K.; ANGEL, J.F. et al. The influence of methionine intake on egg composition. Poult. Sci., v.70, suppl., p.151, 1991. Abstract.

FERREIRA, D.F. Sistema de análises de variância para dados balanceados. Lavras: UFLA, 2000. (SISVAR 4. 1. - pacote computacional).
FLETCHER, D.L.; BRITTON, W.M.; RAHN, A.P. et al. The influence of layer flock age on egg component yields and solids content. Poult. Sci., v.60, p.983-987, 1981.

HARMS, R.H.; RUSSEL, G.B.; HARLOW, H. et al. The influence of methionine on commercial laying hens. J. Appl. Poult. Res., v.7, p.45-52, 1998.

ISHIBASHI, T.; YONEMOCHI, C. Amino acid nutrition in egg production industry. Anim. Sci. J., v.74, p.457-469, 2003.

LEESON, S.; SUMMERS, J.D. Nutrition of the chicken. 4.ed. Guelph: University Books, 2001. 591p.

LIU, Z.; WU, G.; BRYANT, M.M. et al. A. Influence of added synthetic lysine in lowprotein diets with the methionine plus cysteine to lysine ratio maintained at 0,75. J. Appl. Poult. Res. v.14, p.174-182, 2005.

NOVAK, C.; SCHEIDELER, S. The effect of protein levels and TSAA: lysine ratio on egg production parameters, egg yield and molecular components in tissues. In: MARYLAND CONFERENCE FOR FEED MANUFACTURERS, 50; MID-ATLANTIC NUTRITION CONFERENCE, 1., 2003, College Park. Proceedings... College Park: University of Maryland, 2003. p.39-51.

NOVAK, C.; YAKOUT, H.; SCHEIDELER, S. The combined effects of lysine and total sulfur amino acid level on egg production parameters and egg components in Dekalb Delta laying hens. Poult. Sci., v.83, p.977-984, 2004.

NUTRIENT requirement of poultry. 9.ed. Washington, DC: National Academy, 1994. $155 \mathrm{p}$.

OFFICIAL methods of analysis. 15.ed. Wasginhton: AOAC, 1990.

PENZ, A.M.; JENSEN, L.S. Influence of protein concentration, amino acid supplementation, and daily time of acess to high or low protein diets on egg weight and components in laying hens. Poult. Sci., v.70, p.2460-2466, 1991.

ROLAND, D.A.; YADALAM, S.; BRYANT, M. Why the NRC and commonly recommended $\mathrm{M}+\mathrm{C} / \mathrm{lysine}$ ratio for commercial Leghorns is incorrect: $\mathrm{n}^{\circ} 1$. Poult. Sci., v.79, suppl., p.92, 2000. (Abstract). 
ROSTAGNO, H.S.; ALBINO, L.F.T.; DONZELE, J.L. et al. Tabelas brasileiras para aves e suínos: composição de alimentos $\mathrm{e}$ exigências nutricionais. Viçosa: UFV, 2005. $186 \mathrm{p}$.

SCHEIDELER, S.E.; ELLIOT, M.A. Total sulfur amino acid (TSAA) intake to maximize egg mass and feed efficiency in young layers (19-45 weeks of age). Poult. Sci., v.77, suppl. 1, p.130, 1998. (Abstract).
SHAFER, D.J.; CAREY, J.B.; PROCHASKA, J.F. et al. Dietary methionine intake effects on egg component yield, composition, functionality, and texture profile analysis. Poult. Sci., v.77, p.1056-1062, 1998.

SOHAIL, S.S.; BRYANT, M.M.; ROLAND, D.A. Influence of supplemental lysine, isoleucine, treonine, tryptophan and total sulfur amino acids on egg weight of Hy Line W36 hens. Poult. Sci., v.81, p.1038-1044, 2002. 